\title{
Remarkable Expansion of the Poly(acrylic acid) Chain by Acid-Base Complexation with Low Molecular Weight Amines
}

\author{
Yuki KIMURA and Takahiro SATO ${ }^{\dagger}$ \\ Department of Macromolecular Science, Osaka University, \\ 1-1 Machikaneyama-cho, Toyonaka 560-0043, Japan
}

(Received August 31, 2005; Accepted October 17, 2005; Published February 15, 2006)

\begin{abstract}
The intrinsic viscosity $[\eta]$ of a poly(acrylic acid) (PAA) sample with a molecular weight of $4 \times 10^{6}$ in aqueous salt solution drastically increased by adding isopropyl amine (A-1). At the infinitely high concentration of the hydrochloric salt of A-1, where the electrostatic interaction is completely screened out, $[\eta]$ was enlarged by 40 times as the degree of complexation $f_{\mathrm{c}}$ increases from $c a$. zero to 0.6 . Here $f_{\mathrm{c}}$ was determined by potentiometric and NMR titrations. Furthermore, $[\eta]$ at infinite ionic strength for PAA complexed with a bulkier and more hydrophobic amine, $(R)-(+)-1$-(phenyl)ethylamine (A-2), was higher than that for the complex of PAA and A-1 at the same $f_{\mathrm{c}}$. The drastic expansion of the PAA chain by the complexation with the amines A-1 and A-2 may arise from the chain stiffening and enhanced excluded volume effect. [DOI 10.1295/polymj.38.190]

KEY WORDS Intrinsic Viscosity / Poly(acrylic acid) / Acid-Base Complexation / Titration /

Degree of Comlexation / Chain Expansion /
\end{abstract}

Recent years, supramolecular polymers have attracted much attention in macromolecular science because of their unique properties and functions not exhibited by conventional polymers. ${ }^{1,2}$ Components of supramolecular polymers are small molecules and/or macromolecules. Small molecular components can assemble by hydrogen bonding, coordinate bonding, acid-base complexation, or hydrophobic interaction to form supramolecular polymers. An example of macromolecular assemblies in the biological field is tobacco mosaic virus. It consists of a RNA molecule covered with a lot of protein molecules under normal conditions to protect the RNA chain, but dissociates the proteins at multiplication. The association and dissociation of protein molecules are key factors of preservation of their posterity.

The combination of a macromolecule and many small molecules is another type of supramolecular polymers. Yashima et al. ${ }^{3,4}$ demonstrated that a dynamical helical polymer, poly((4-carboxyphenyl)acetylene) complexed with optically active low-molarmass amines induced and memorized very strong circular dichroism (CD). The acid-base complexation in this system was much more effective to the CD induction than the normal chiral doping to dynamical helical polymer solutions. Moreover, Ashida et al. ${ }^{5}$ have recently showed that the complexation with an amine stiffens this helical polymer chain in dimethylsulfoxide, indicating that the complexation affects the internal rotation potential of the polymer chain.

In this study, we have investigated the effect of the acid-base complexation to the chain conformation of a non-helical polymer in aqueous solution. As the simplest example, we have chosen poly(acrylic acid) (PAA) and examined the PAA chain expansion by the complexation with low-molar-mass amines [isopropyl amine (A-1) and $(R)-(+)-1$-(phenyl)-ethylamine (A-2)]. The viscometry has demonstrated a remarkable expansion of the PAA chain by the complexation in aqueous solution. This demonstrates that the polymer-chain conformation can change by altering polymer side chains supramolecularly.

In an aqueous solution containing an amine $\mathrm{RNH}_{2}$, the carboxyl group can take the following three forms, the acid form $(-\mathrm{COOH})$, the complex form $\left(-\mathrm{COOH}_{3}-\right.$ $\mathrm{NR})$, and the free ion $\left(-\mathrm{COO}^{-}\right)(c f$. Scheme 1). The fraction of the complex form $f_{\mathrm{c}}$ depends on the concentration of $\mathrm{RNH}_{2}$ and also $\mathrm{pH}$. Along with viscometry, we have undertaken potentiometric and NMR titrations for aqueous solutions containing PAA and amine (A-1 or A-2) to estimate $f_{\mathrm{c}}$, which is the basic parameter to discuss the mechanism of the PAA chain expansion by the complexation.

\section{EXPERIMENTAL}

\section{Preparation of Test Solutions}

A commercial PAA sample (Nacalai Tesque, Japan) was dissolved in water and passed through a mixed-bed ion exchanger [Amberlite IR-120 + IRA$900(1: 2)]$. The eluted solution was freeze dried to obtain the acid-form PAA sample. The intrinsic viscosity

${ }^{\dagger}$ To whom correspondence should be addressed (Tel: +81-6-6850-5461, Fax: +81-6-6850-5461, E-mail: tsato@chem.sci.osaka-u.ac.jp). 


\section{$-\mathrm{COOH}+\mathrm{RNH}_{2} \leftrightarrow-\mathrm{COOH}_{3} \mathrm{NR} \leftrightarrow-\mathrm{COO}^{-}+\mathrm{RNH}_{3}^{+}$}

Scheme 1.

$[\eta]$ of the PAA sample was measured in $1.5 \mathrm{M}$ aqueous $\mathrm{NaBr}$ at $15^{\circ} \mathrm{C}$, after the PAA solution was neutralized with aqueous $\mathrm{NaOH}$. The viscosity average molecular weight of the acid (Na salt) form of the PAA sample was estimated to be $3.67 \times 10^{6}\left(4.79 \times 10^{6}\right)$, using the Mark-Houwink-Sakurada equation for the $\mathrm{Na}$ salt form of PAA in that solvent condition (the $\theta$ state) reported by Takahashi and Nagasawa. ${ }^{6}$

Isopropyl amine (A-1) and $(R)-(+)-1-($ phenyl)ethylamine (A-2) purchased (Wako chemicals, Japan) were used without purification. Water used was purified by Milli-Q SP.

The dried PAA sample was dissolved in aqueous solutions of A-1 with different amine concentrations, and $p H$ of the PAA solutions and also solvents (aqueous amine solutions) were adjusted to $3,4,5,7$, and 10 by using $0.1-1 \mathrm{~N} \mathrm{HCl}$. Aqueous PAA solutions containing A-2 with different amine concentrations and $p H=7$ were also prepared in a similar way. The addition of aqueous $\mathrm{HCl}$ was taken into account to calculate the mass concentration $c$ of PAA in the solution and the molar concentration $C_{\mathrm{A}}^{\circ}$ of total amine in the solvent. Our solvent is a ternary system consisting of an amine, hydrochrolic salt of the amine, and water. The molar concentrations of amine $\left(C_{\mathrm{A}}\right)$ and its $\mathrm{HCl}$ salt $\left(C_{\mathrm{s}}\right)$ in the solvent can be calculated by $C_{\mathrm{A}}=C_{\mathrm{A}}^{\circ}-C_{\mathrm{HCl}}$ and $C_{\mathrm{s}}=C_{\mathrm{HCl}}$, respectively, where $C_{\mathrm{HCl}}$ is the molar concentration of added $\mathrm{HCl}$ in the solvent. In what follows, the solvent condition is specified either in terms of $C_{\mathrm{A}}^{\circ}$ and $p H$ or of $C_{\mathrm{A}}$ and $C_{\mathrm{s}}$.

\section{Viscometry}

Viscosities of the above aqueous solution containing PAA, amine, and its $\mathrm{HCl}$ salt were measured at $25^{\circ} \mathrm{C}$ using a Ubbelohde-type capillary viscometer. For solutions with $p H=10$, the shear rate dependence of the viscosity was examined using a lowshear-rate four bulb capillary viscometer. ${ }^{7,8}$ After measured the viscosity, the original solution was diluted with the solvent with the same $C_{\mathrm{A}}^{\circ}$, and $p H$ in the viscometer, and the viscosity measurement was made again to obtain the PAA concentration dependence of the solution viscosity at the constant $C_{\mathrm{A}}^{\circ}$ and $p H$. The intrinsic viscosity $[\eta]$ at each $C_{\mathrm{A}}^{\circ}$ and $p H$ was determined from the common intercept of the following Huggins and Mead-Fuoss plots:

$$
\eta_{\mathrm{sp}} / c=[\eta]+k^{\prime}[\eta]^{2} c^{2}+\cdots
$$

$$
\left(\ln \eta_{\mathrm{r}}\right) / c=[\eta]-\left(\frac{1}{2}-k^{\prime}\right)[\eta]^{2} c^{2}+\cdots
$$

where $\eta_{\mathrm{sp}}$ and $\eta_{\mathrm{r}}$ are the specific and relative viscosities, respectively, and $k^{\prime}$ is the Huggins coefficient.

\section{Potentiometric Titration}

Potentiometric titration measurements were made using a $\mathrm{pH}$ meter (Horiba, $\mathrm{F}-23$ ) for aqueous $\mathrm{NaCl}$ solutions of PAA with $c=1.4 \times 10^{-4} \mathrm{~g} / \mathrm{cm}^{3}$ or the molar concentration of the carboxyl group $C_{\mathrm{C}}=0.002 \mathrm{M}$ (before titration) and different ionic strength $I$ using $0.05 \mathrm{~N}$ aqueous $\mathrm{NaOH}$ as the titrant. The degree of ionization $f_{-}$of the carboxyl group was estimated by

$$
f_{-}=\frac{C_{\mathrm{NaOH}}+\left[\mathrm{OH}^{-}\right]-\left[\mathrm{H}^{+}\right]}{C_{\mathrm{C}}}
$$

where $C_{\mathrm{NaOH}}$ is the molar concentrations of $\mathrm{NaOH}$ titrated. The molar concentrations of the hydrogen ion $\left[\mathrm{H}^{+}\right]$and the hydroxyl ion $\left[\mathrm{OH}^{-}\right]$were calculated from $\mathrm{pH}$ of the solution. The dilution of the test solution during titration was taken into account to calculate $C_{\mathrm{NaOH}}$ and $C_{\mathrm{C}}$ in eq 3 . The dissociation constant $K_{\mathrm{C}}$ of the carboxyl group was estimated by

$$
K_{\mathrm{C}}=\left[\mathrm{H}^{+}\right] f_{-} /\left(1-f_{-}\right)
$$

as a function of $f_{-}$and ionic strength $I$.

It is known that the dissociation constant of the low-molar-mass acid and the protonation constant of low-molar-mass amine are independent of $f_{-}$and $I$. From $p H$ measurements, the dissociation constant $K_{\mathrm{C}}^{\prime}$ of isobutylic acid (a model compound for PAA; see below) was determined to be $1.59 \times 10^{-5} \mathrm{M}$, while protonation constants $K_{\mathrm{A}}$ for A-1 and A-2 were determined to be $1.45 \times 10^{11}$ and $4.57 \times 10^{9} \mathrm{M}^{-1}$, respectively.

\section{NMR Titration}

NMR measurements were made at $25^{\circ} \mathrm{C}$ for $\mathrm{D}_{2} \mathrm{O}$ solutions of isobutylic acid and amine A-1 with the molar concentrations $C_{\mathrm{C}}(=0.11 \mathrm{M})$ and $C_{\mathrm{A}}$ $(=0-0.2 \mathrm{M})$, respectively using an Excallibur 400 NMR spectrometer. Here isobutylic acid was used as the model compound for PAA, and a trace amount of acetonitrile was added to the solutions as the standard material.

Figure 1a shows NMR spectra of $\mathrm{D}_{2} \mathrm{O}$ solutions of isobutylic acid and A-1 with three different ratios $C_{\mathrm{A}} / C_{\mathrm{C}}$. From the chemical shift $\delta$ for the central peak of the isobutylic acid methyne signal around 2.3-2.5 ppm, the mole fraction $f_{\mathrm{a}}$ of the acid form of isobutylic acid in the solution was estimated by

$$
f_{\mathrm{a}}=\frac{\delta-\delta_{0}}{\delta_{1}-\delta_{0}}
$$

and 


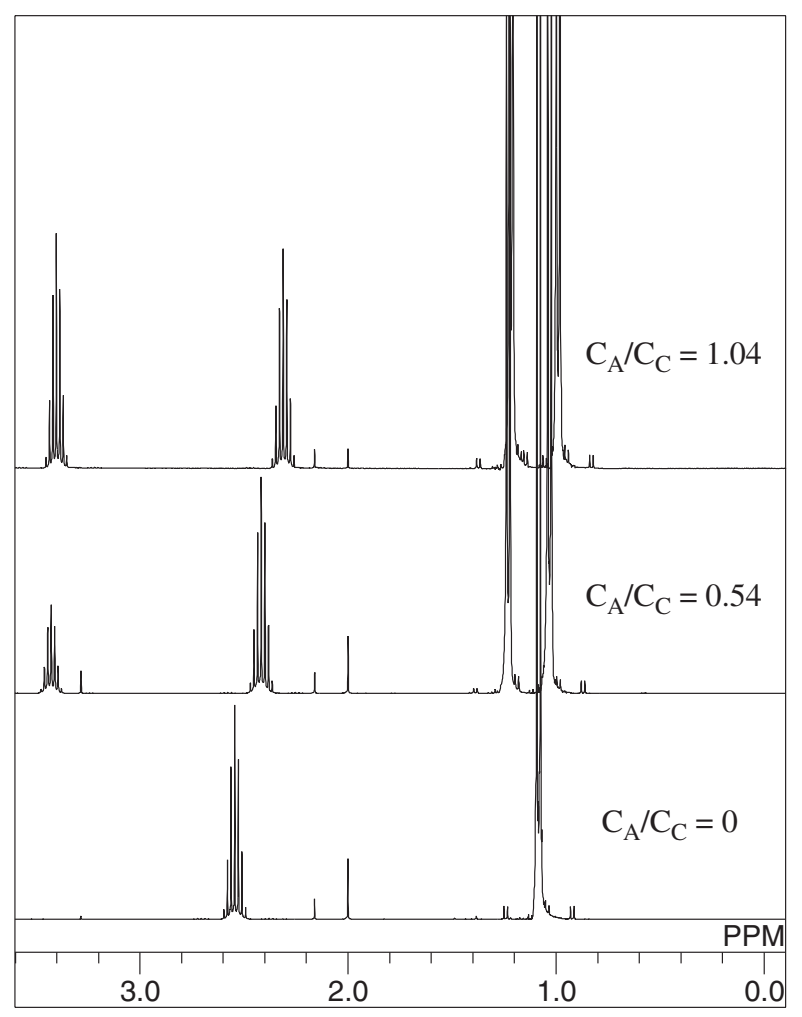

(a)



(b)

Figure 1. (a) NMR spectra of $\mathrm{D}_{2} \mathrm{O}$ solutions containing isobutylic acid (a model compound of PAA) and amine A-1 with three different ratios $C_{\mathrm{A}} / C_{\mathrm{C}}$; (b) the mole fraction $f_{\mathrm{a}}$ of the acid form of isobutylic acid in aqueous A-1 solution as a function of $C_{\mathrm{A}} / C_{\mathrm{C}}$, where the solid line indicates theoretical values calculated by eq 6 with $K_{\mathrm{C}}^{\prime}=1.59 \times 10^{-5} \mathrm{M}, K_{\mathrm{A}}=1.45 \times 10^{11} \mathrm{M}^{-1}$, and $K=4.7 \times 10^{6} \mathrm{M}^{-1}$.

where $\delta_{0}(=2.544 \mathrm{ppm})$ and $\delta_{1}(=2.311 \mathrm{ppm})$ are the chemical shifts at $C_{\mathrm{A}} / C_{\mathrm{C}}=0$ and in the saturated state, respectively.

The mole fraction $f_{\mathrm{a}}$ may be calculated from the complexation constant $K$ ( $c f$. eq A.4 in Appendix), the dissociation constant $K_{\mathrm{C}}^{\prime}$ of isobutylic acid, and the protonation constant $K_{\mathrm{A}}$ of the amine by solving the following simultaneous equations:

$$
\left\{\begin{array}{l}
f_{\mathrm{a}}=\left(1+K_{\mathrm{C}}^{\prime} /\left[\mathrm{H}^{+}\right]+K\left[\mathrm{RNH}_{2}\right]\right)^{-1} \\
{\left[\mathrm{RNH}_{2}\right]=\frac{C_{\mathrm{A}}}{1+K_{\mathrm{A}}\left[\mathrm{H}^{+}\right]+K C_{\mathrm{C}} f_{\mathrm{a}}}} \\
{\left[\mathrm{H}^{+}\right]=\sqrt{\frac{10^{-14}+K_{\mathrm{C}}^{\prime} C_{\mathrm{C}} f_{\mathrm{a}}}{1+K_{\mathrm{A}}\left[\mathrm{RNH}_{2}\right]}}}
\end{array}\right.
$$

When $K$ is chosen to be $4.7 \times 10^{6} \mathrm{M}^{-1}$, and $K_{\mathrm{C}}^{\prime}$ and $K_{\mathrm{A}}$ determined by potentiometric titration (see above) were used in the above equations, theoretical $f_{\mathrm{a}}$ values indicated by the solid line in Figure $1 \mathrm{~b}$ fit the experimental data points. This value of $K$ was confirmed by potential titration, and was taken to be identical with that for PAA and the amine in what follows. In a similar way, $K$ between isobutylic acid and A-2 was determined to be $1.4 \times 10^{5} \mathrm{M}^{-1}$.

\section{RESULTS AND DISCUSSION}

\section{Intrinsic Viscosities}

Figure 2 compares the Huggins and Mead-Fuoss plots for PAA-A1 solutions with $C_{\mathrm{A}}^{\circ}=0.05 \mathrm{M}$ and $p H=7$ prepared in the way mentioned in Experimental Section (Panel a) with the plots for PAA directly

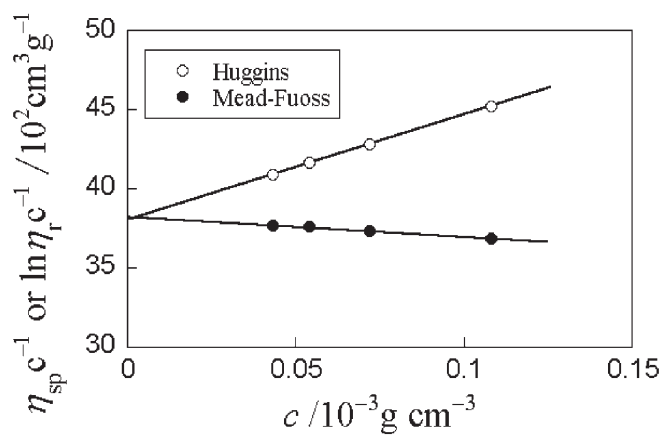

(a)

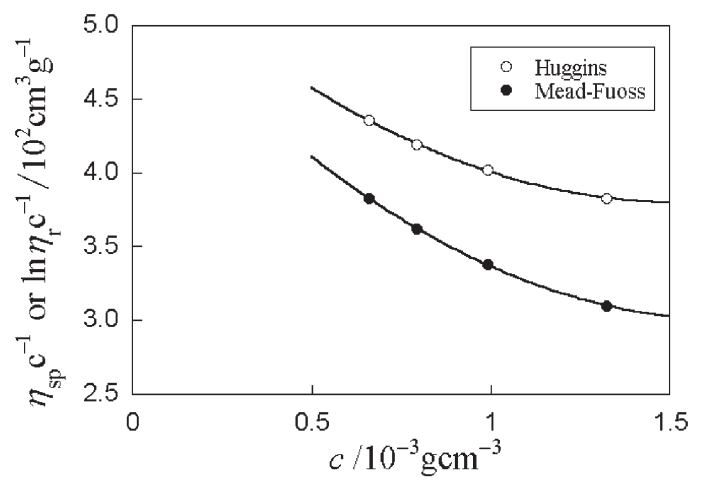

(b)

Figure 2. Huggins and Mead-Fuoss plots for PAA-A1 solutions with $C_{\mathrm{A}}^{\circ}=0.05 \mathrm{M}$ and $p H=7$; (a) PAA solution prepared in the way mentioned in Experimental Section with adjusting $p H$; (b) PAA directly dissolved in A-1 solution without adjusting $p H$. 




Figure 3. Shear rate dependencies of the intrinsic viscosity at $p H=10$ and different $C_{\mathrm{A}}^{\circ}$ of A-1.

dissolved in an A-1 solution with $C_{\mathrm{A}}^{\circ}=0.05 \mathrm{M}$ and $p H=7$ (Panel b). Since $p H$ of the solution in Panel b was not adjusted after dissolution of PAA, $p H$ increased with decreasing $c$. As the result, the plots showed strongly upswing $c$ dependencies, and it was difficult to determine the intrinsic viscosity $[\eta]$. On the other hand, $p H$ of the PAA-A1 solution in Panel a was adjusted to 7 , and $[\eta]$ was estimated from the plots with the normal $c$ dependencies without any difficulty.

Apparent shear rate $\dot{\gamma}$ dependencies of $[\eta]$ for PAA-A1 solutions with $p H=10$ and different $C_{\mathrm{A}}^{\circ}$ are shown in Figure 3. With decreasing $C_{\mathrm{A}}^{\circ}$ (or ionic strength), the absolute value of $[\eta]$ increases and its shear rate dependence becomes stronger. We have determined $[\eta]$ at $\dot{\gamma}=0$ by extrapolation at $p H=10$.

Figure 4 shows $C_{\mathrm{A}}^{\circ}$ and $p H$ dependencies of $[\eta]$ and the Huggins coefficient $k^{\prime}$ for PAA-amine solutions. In Panel a, $[\eta]$ decreases with increasing $C_{\mathrm{A}}^{\circ}$ and decreasing $p H$ in A-1 solution, and the $p H$ dependence is drastic. At $p H=7,[\eta]$ in A-2 solution is lower than that in A-1 solution within the $C_{\mathrm{A}}^{\circ}$ range examined, and its $C_{\mathrm{A}}^{\circ}$ dependence is weaker than that in $\mathrm{A}-1$ solution. At $p H=10$, the zero-shear-rate $[\eta]$ (filled circles) are larger than those at a $\dot{\gamma}$ of $c a .10^{3} \mathrm{~s}^{-1}$ (unfilled circles). In Panel $\mathrm{b}, k^{\prime}$ are mostly within a range of 0.3-0.55, indicating normal dissolution of PAA in the amine solutions. Only at $C_{\mathrm{A}}^{\circ}=0.42 \mathrm{M}$ and $p H=$ $3, k^{\prime}$ is exceptionally large. The degree of ionization of PAA is low while the ionic strength is high in that solvent condition, and thus the solubility of PAA to this amine solution is quite low. The large $k^{\prime}$ may reflect this poor solubility.

In Figure 5, $[\eta]$ of PAA in aqueous amine and its hydrochloric salt solutions are plotted against the reciprocal of the square root of the hydrochloric salt concentration $C_{\mathrm{s}}$. The $C_{\mathrm{s}}$ dependence of $[\eta]$ is more pronounced at higher $p H$. Using the lines shown in Figure 5, we have extrapolated $[\eta]$ to the infinite $C_{\mathrm{s}}$

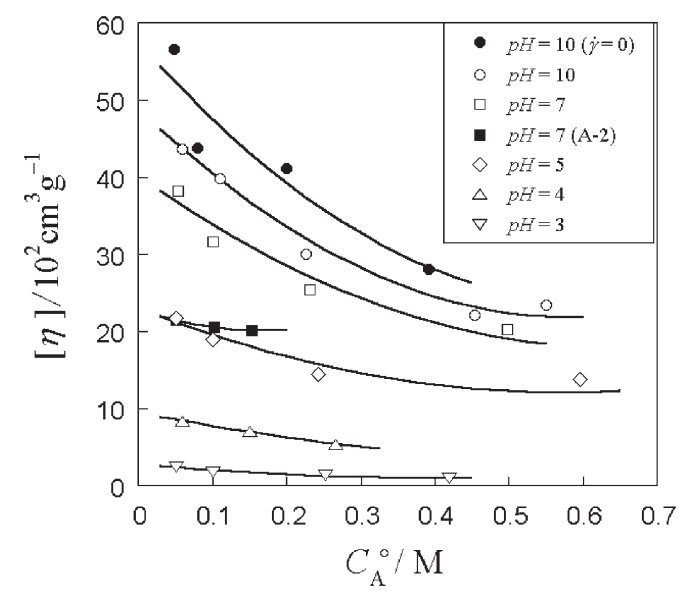

(a)

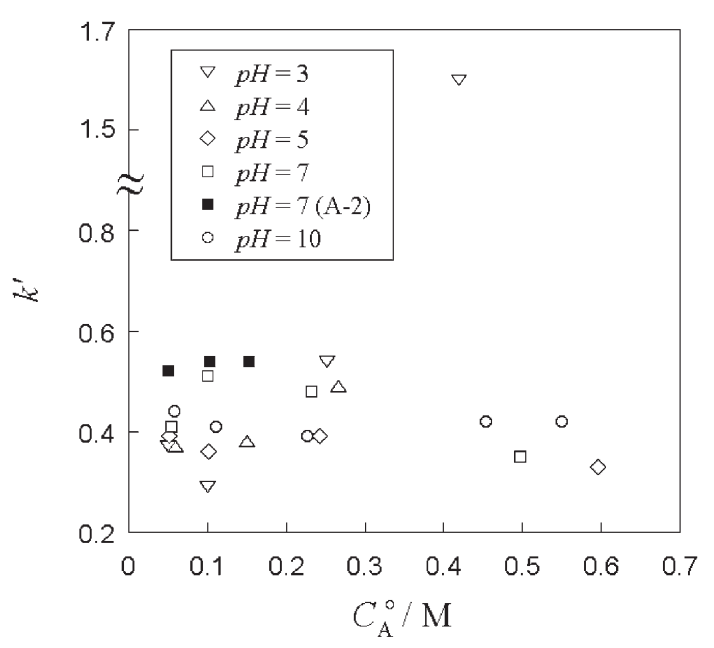

(b)

Figure 4. $C_{\mathrm{A}}^{\circ}$ and $p H$ dependencies of (a) the intrinsic viscosity $[\eta]$ and of (b) the Huggins coefficient $k^{\prime}$. Data points except for filled squares are for PAA-A1 solutions.

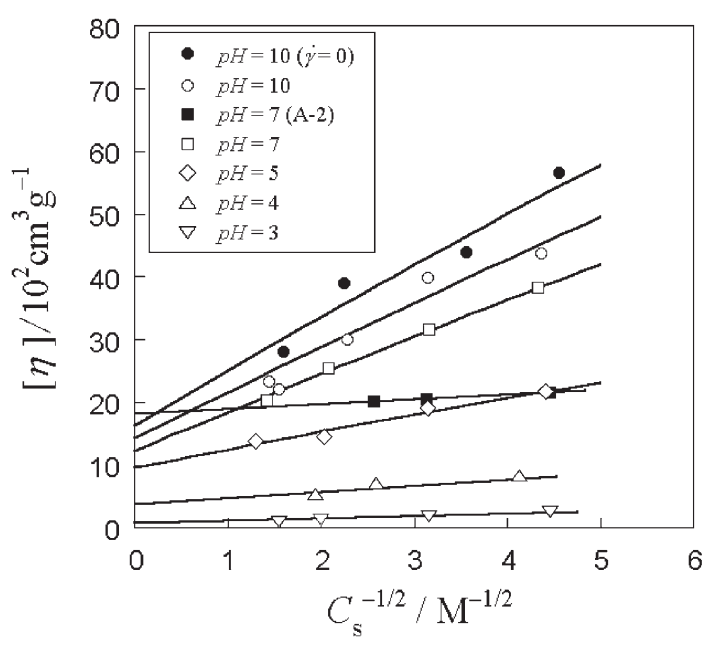

Figure 5. Plots of $[\eta]$ against $C_{\mathrm{s}}^{-1 / 2}$ for aqueous amine solutions of PAA at different $p H$; filled squares, data for PAA-A2 solutions; other symbols, data for PAA-A1 solutions. 
where the electrostatic interaction is fully screened out. At $p H=10$, the zero-shear rate $[\eta]$ are extrapolated to infinite $C_{\mathrm{s}}$, and the result is slightly larger than that without the shear rate correction. Although we did not examine the shear rate dependence of $[\eta]$ at $p H$ other than 10 , we may expect that the non-Newtonian effect is not so important at the infinite $C_{\mathrm{s}}$ for our PAA sample at all $p H$ examined.

Figure 5 contains also the results of PAA complexed with amine A-2 at $p H=7$. The $C_{\mathrm{s}}$ dependence of $[\eta]$ for this complex is much weaker and its extrapolated $[\eta]$ is larger than that for the complex with A-1 at the same $p H$. The amine A-2 is more hydrophobic than A-1 and thus the affinity of the PAA chain complexed with A-2 to water may be poorer than the PAA-A1 complex. Since the increase of $C_{\mathrm{s}}$ (or the concentration of the hydrochrolic salt of A-2) makes the solvent quality better, the excluded volume effect of the PAA-A2 complex should be enhanced with increasing $C_{\mathrm{s}}$. This effect may compensate the reduction of the electrostatic excluded volume effect.

The intrinsic viscosity $[\eta]_{\infty}$ extrapolated to infinite $C_{\mathrm{s}}$ is plotted against $p H$ in Figure 6. In general, both degrees of ionization and complexation increase with increasing $\mathrm{pH}$, and both contribute to the increase in $[\eta]$. However, we can expect only the contribution of the acid-amine complexation to $[\eta]_{\infty}$, because the electrostatic interaction is not important at $C_{\mathrm{s}}=\infty$. At $p H=7,[\eta]_{\infty}$ for the PAA-A2 complex (filled circle in Figure 6) is larger than that for the PAA-A1 complex. The complexation of the bulkier and more hydrophobic amine A-2 expands more the PAA chain.

\section{Degrees of Complexation and Ionization}

As shown in Scheme 1, the carboxyl group attaching to PAA chain can take one of the three states, the acid, complex, and free ion forms. Both complexation

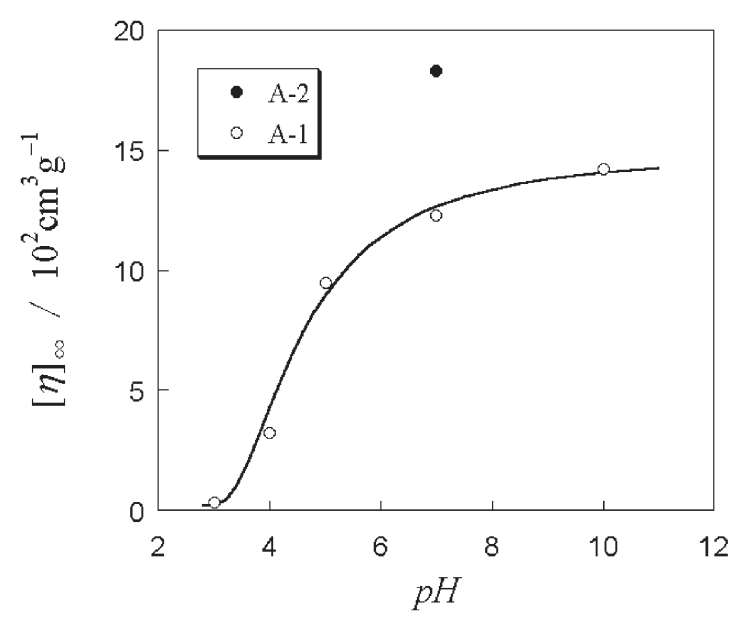

Figure 6. $[\eta]_{\infty}$ plotted against $p H$ for PAA complexed with A-1 (unfilled circles) and A-2 (filled circle). and ionization change the PAA chain conformation through the chain stiffening and intramolecular excluded volume effect. The degrees of complexation $f_{\mathrm{c}}$ and of ionization $f_{-}$at given $C_{\mathrm{A}}^{\circ}$ and $p H$ can be calculated by eqs A.5 and A.6 in Appendix from the complexation constant $K$ and the dissociation constant $K_{\mathrm{c}}$.

Figure 7a shows $K_{\mathrm{c}}$ of PAA in aqueous $\mathrm{NaCl}$ solutions, determined by potentiometric titration. In general, $K_{\mathrm{c}}$ for polyelectrolytes depends on the polymer degree of ionization $f_{-}$and ionic strength $I$. Using these results of $K_{\mathrm{c}}$ as well as $K$ from the NMR titration (cf. Experimental Section), we have calculated $f_{\mathrm{c}}$ and $f_{-}$ for PAA (at infinitely dilution) in aqueous solutions of amine and its hydrochloric salt. (Since $K_{\mathrm{c}}$ depends on $f_{-}$, the calculated $f_{-}$must be consistent with $K_{\mathrm{c}}$ at that $f_{-}$, and we made iterative calculations to obtain $f_{\mathrm{c}}$ and $f_{-}$). The results of $f_{\mathrm{c}}$ and $f_{-}$are shown in Figure 7b. Both $f_{\mathrm{c}}$ and $f_{-}$increase with $p H$ and almost saturate above $p H=7$. The $C_{\mathrm{s}}$ dependencies of $f_{\mathrm{c}}$ and $f_{-}$are strong at $p H=4$ and 5, but rather weak at other $p H$. Using the curves indicated, we have estimated the degree of complexation $f_{\mathrm{c}, \infty}$ at infinite ionic strength $I$.

Figure 8 plots $[\eta]_{\infty}$ against $f_{\mathrm{c}, \infty}$, obtained in Figures 5 and $7 \mathrm{~b}$, respectively. For the complex with amine A-1 (unfilled circles), $[\eta]_{\infty}$ enlarges by $c a .40$ times as $f_{\mathrm{c}, \infty}$ increases from $c a$. zero to 0.6. Although the degree of ionization $f_{-, \infty}$ at infinite $I$ increases along with $f_{\mathrm{c}, \infty}(c f$. Figure $7 \mathrm{~b}$ ), the ionization may not contribute to $[\eta]_{\infty}$ because the electrostatic interaction is completely screened out at $C_{\mathrm{s}}$ or $I=\infty$. Therefore, we can say that the complexation with amine A-1 remarkably increases the PAA chain dimension. Furthermore, the complexation with bulkier and more hydrophobic amine A-2 increases the PAA chain dimension more at the same $f_{\mathrm{c}, \infty} \sim 0.6$.

The complexation with amine may restrict the internal rotation of the PAA main chain, which can stiffen the PAA main chain. This is one of reasons for the chain expansion by the complexation. Recently, Ashida et al. ${ }^{5}$ reported that the persistence length of a stiff helical polymer, poly((4-carboxyphenyl)acetylene), increased twice (from 4.2 to $8.6 \mathrm{~nm}$ ) by complexation with an optically active amine $[(R)-(+)-1-$ (1-naphtyl)ethylamine] in dimethylsulfoxide, and attributed the stiffening to the reduction of the torsional fluctuation by the steric hindrance among amines complexed with the polymer. On the other hand, the complexation with amine makes the affinity of the chain to the solvent with infinite $C_{\mathrm{s}}$ of the hydrochloric salt of the amine better, which enhances the excluded volume effect. Since PAA is a flexible chain, the excluded volume effect may be also an important factor of the chain expansion by complexation with amine. 


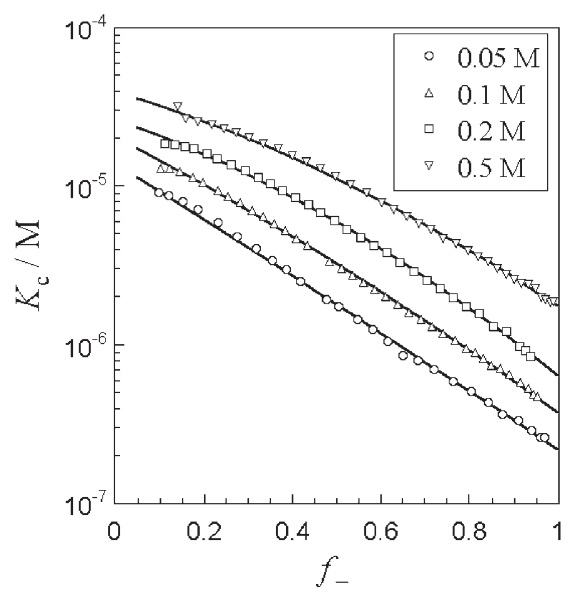

(a)
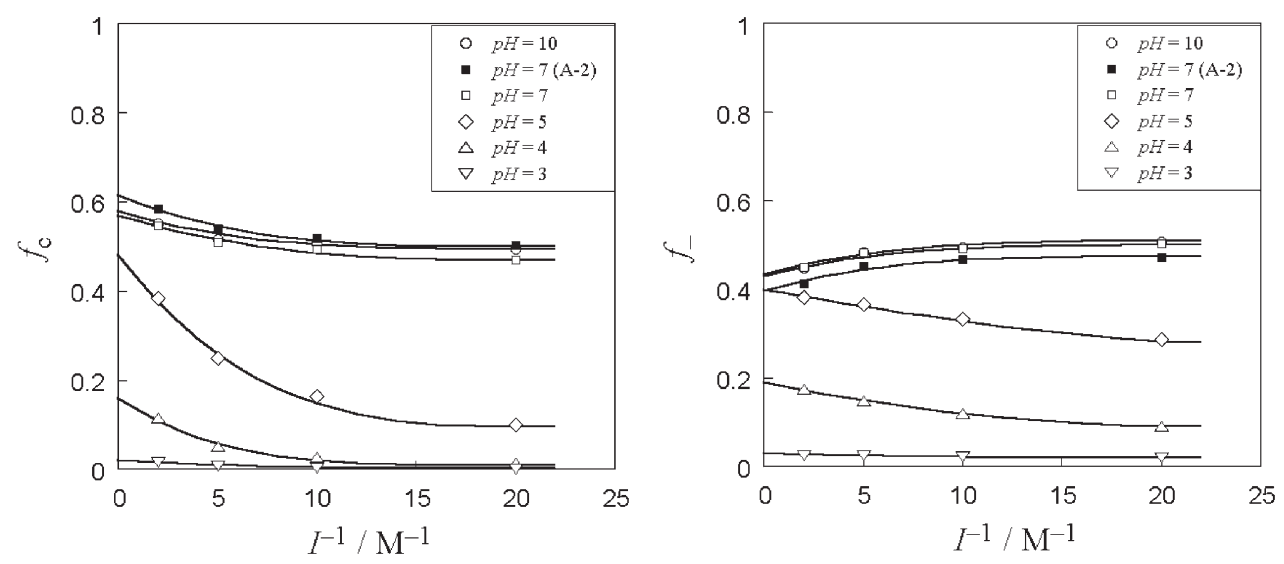

(b)

Figure 7. (a) Dissociation constant $K_{\mathrm{C}}$ of PAA in aqueous $\mathrm{NaCl}$ solution at different $f_{-}$and $I$, and (b) $f_{\mathrm{c}}$ and $f_{-}$of PAA in amine solutions at different $p H$ and $I$; data points other than filled squares, for PAA in A-1 solutions.

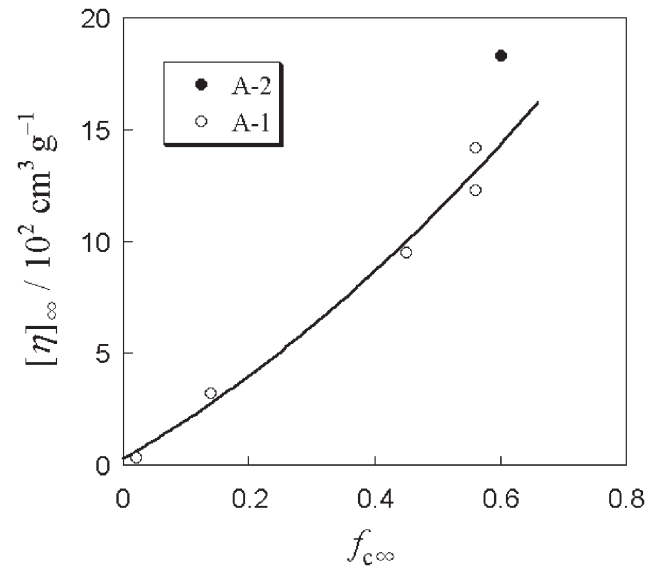

Figure 8. Plots of $[\eta]_{\infty}$ against $f_{\mathrm{c}, \infty}$ for PAA complexed with amines A-1 (unfilled circles) and A-2 (filled circle).

\section{APPENDIX: DEGREES OF COMPLEXATION AND IONIZATION}

Let us consider an aqueous solution containing an amine $\mathrm{RNH}_{2}$ and its hydrochloric salt $\mathrm{RNH}_{3} \mathrm{Cl}$. The salt $\mathrm{RNH}_{3} \mathrm{Cl}$ is assumed to be perfectly dissociated into $\mathrm{RNH}_{3}{ }^{+}$and $\mathrm{Cl}^{-}$in the aqueous solution. The molar concentrations $\left[\mathrm{RNH}_{3}{ }^{+}\right]$and $\left[\mathrm{RNH}_{2}\right]$ are calculated from the electro-neutral condition and mass conservation rule, respectively, by

$$
\left[\mathrm{RNH}_{3}{ }^{+}\right]=C_{\mathrm{HCl}}+\left[\mathrm{OH}^{-}\right]-\left[\mathrm{H}^{+}\right]
$$

and

$$
\left[\mathrm{RNH}_{2}\right]=C_{\mathrm{A}}^{\circ}-\left[\mathrm{RNH}_{3}{ }^{+}\right]
$$

Here $C_{\mathrm{HCl}}$ is the concentration of hydrochloric acid added to adjust $p H, C_{\mathrm{A}}^{\circ}$ is the total amine concentration in the solution, and the molar concentrations of the hydrogen ion $\left[\mathrm{H}^{+}\right]$and hydroxyl ion $\left[\mathrm{OH}^{-}\right]$are calculated from $\mathrm{pH}$ of the solution.

When a carboxylic acid is added to the above aqueous solution of $\mathrm{RNH}_{2}$ and $\mathrm{RNH}_{3} \mathrm{Cl}$, it can take one of the three forms: the acid form $-\mathrm{COOH}$, the complex form $-\mathrm{COOH}_{3} \mathrm{NR}$, and the free ion $-\mathrm{COO}^{-}(c f$. Scheme 1). Under the equilibrium condition, the molar concentrations of the three forms are related to each other by 


$$
K_{\mathrm{C}}=\left[-\mathrm{COO}^{-}\right] \cdot\left[\mathrm{H}^{+}\right] /[-\mathrm{COOH}]
$$

and

$$
K=\left[-\mathrm{COONH}_{3} \mathrm{R}\right] /\left([-\mathrm{COOH}] \cdot\left[\mathrm{RNH}_{2}\right]\right)
$$

where $K_{\mathrm{C}}$ and $K$ are the equilibrium constants of dissociation and complexation, respectively. If the acid concentration is infinitely dilute, we can calculate the degrees of complexation $f_{\mathrm{c}}$ and of ionization $f_{-}$ from the above relations by

$$
f_{\mathrm{c}}=\frac{K\left[\mathrm{RNH}_{2}\right]}{1+\left(K_{\mathrm{c}} /\left[\mathrm{H}^{+}\right]\right)+K\left[\mathrm{RNH}_{2}\right]}
$$

and

$$
f_{-}=\frac{\left[\mathrm{H}^{+}\right] / K_{\mathrm{c}}}{1+\left(K_{\mathrm{c}} /\left[\mathrm{H}^{+}\right]\right)+K\left[\mathrm{RNH}_{2}\right]}
$$

where $\left[\mathrm{RNH}_{2}\right]$ can be estimated from eqs $\mathrm{A} \cdot 1$ and A.2.

Acknowledgment. We are grateful to Professor Yoshiyuki Einaga at Nara Women's University for his valuable comment on this work. This work was partly supported by a Grant-in-Aid for Scientific Research from the Japan Society for the Promotion of Science.

\section{REFERENCES}

1. "Supramolecular Polymers," A. Ciferri, Ed., Marcel Dekker, New York \& Basel, 2000.

2. L. Brunsveld, B. J. B. Folmer, E. W. Meijer, and R. P. Sijbesma, Chem. Rev., 101, 4071 (2001).

3. E. Yashima, K. Maeda, and Y. Okamoto, Nature, 399, 449 (1999).

4. E. Yashima, T. Matsushima, and Y. Okamoto, J. Am. Chem. Soc., 119, 6345 (1997).

5. Y. Ashida, T. Sato, K. Morino, K. Maeda, Y. Okamoto, and E. Yashima, Macromolecules, 36, 3345 (2003).

6. A. Takahashi and M. Nagasawa, J. Am. Chem. Soc., 86, 543 (1963).

7. J. H. Larkins, J. D. Perrings, G. R. Shepherd, and B. J. Noland, J. Chem. Educ., 42, 555 (1965).

8. Y. Einaga, Y. Miyaki, and H. Fujita, J. Polym. Sci., Polym. Phys. Ed., 17, 2103 (1979). 